\title{
VISCERAL ADIPOSITY INDEX AS A TOOL FOR CARDIOMETABOLIC RISK IN OBESE OLDER WOMEN
}

\author{
Índice de adiposidade visceral como ferramenta \\ para avaliar o risco cardiometabólico em idosas obesas
}

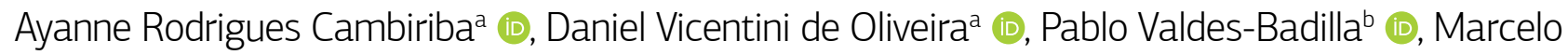

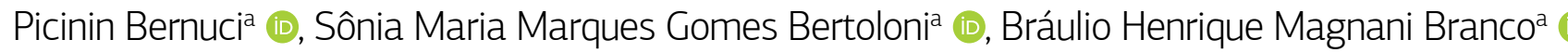

\begin{abstract}
OBJECTIVE: To correlate anthropometric measurements, lipid profile, cardiorespiratory fitness, and visceral adiposity index (VAI) in sedentary obese older women. METHODS: Twenty-seven insufficiently active and overweight older women were included in this cross-sectional study. We evaluated their anthropometric profile (body weight and stature, body mass index, waist and hip circumferences) and body composition (fat mass, body fat percentage, and musculoskeletal mass). Venous blood samples were analyzed for high and low-density lipoproteins (HDL-C and LDL-c), triglycerides (TG), and the LDL/HDL ratio. Peak oxygen uptake ( $\mathrm{VO}_{2}$ peak) was measured using an adapted Bruce test using direct spirometry. We tested data normality and applied Pearson's correlation, assuming a $p \leq 0.05$. RESULS: The following correlations were observed: VAl and HDL $(r=-0.53)$; VAl and LDL ( $r=0.35)$; VAl and TG ( $r=0.86)$; VAl and TG/HDL ( $r=0.99)$ and VAl and $\mathrm{VO}_{2}$ peak $(r=-0.55)$, with $p<0.01$ for all analyses. CONCLUSION: The findings suggested that VAl may be used as a tool to assess cardiometabolic risk in obese older women. Future studies should evaluate the applicability of VAl as a cardiometabolic risk factor indicator in older adults.

KEYWORDS: obesity; aging; aged.

OBJETIVO: Correlacionar medidas antropométricas, perfil lipídico, aptidão cardiorrespiratória e índice de adiposidade visceral (IAV) em idosas obesas sedentárias. METODOLOGIA: Vinte e sete idosas insuficientemente ativas e com sobrepeso foram incluídas neste estudo transversal. Foram avaliados o perfil antropométrico (peso corporal e estatura, índice de massa corporal, circunferências da cintura e quadril) e composição corporal (massa gorda, percentual de gordura corporal e massa ○ musculoesquelética). Amostras de sangue venoso foram analisadas para lipoproteínas de alta e baixa densidade (HDL-c e LDL$\sum_{\supset}$ c), triglicerídeos (TG) e a relação LDL/HDL. O consumo de oxigênio de pico $\left(\mathrm{VO}_{2}\right.$ pico) foi medido usando um teste de Bruce adaptado usando espirometria direta. Testamos a normalidade dos dados e aplicamos a correlação de Pearson, assumindo um $p \leq 0,05$. RESULTADOS: Foram observadas as seguintes correlações: IAV e HDL ( $r=-0,53)$; IAV e LDL ( $r=0,35)$; IAV e TG $(r=0,86)$; IAV e TG/HDL ( $r=0,99)$; e IAV e VO 2 pico $(r=-0,55)$, com $p<0,01$ para todas as análises. CONCLUSÃO: Os achados sugerem que o IAV pode ser utilizado como ferramenta para avaliar o risco cardiometabólico em idosas obesas. Estudos futuros devem avaliar a aplicabilidade do IAV como indicador de fator de risco cardiometabólico em idosos.
\end{abstract}

PALAVRAS-CHAVE: obesidade; envelhecimento; idoso.

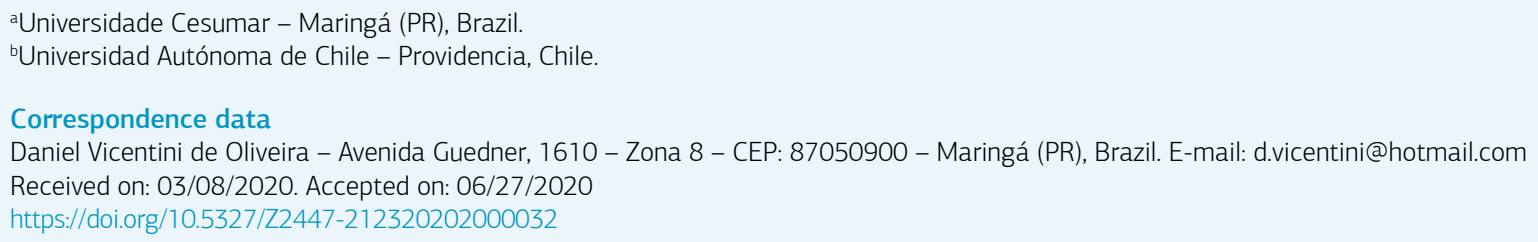




\section{INTRODUCTION}

Over the past decades, the prevalence of cardiometabolic risk factors - hypertension, impaired glucose regulation, and dyslipidemia - has increased worldwide. This scenario mostly results from changes in social and behavioral factors, such as population aging, rapid urbanization, and unhealthy lifestyles characterized by physical inactivity and poor diet, commonly seen in low- and middle-income countries. ${ }^{1}$

Although men and women are both susceptible to cardiometabolic disorders, the health consequences are sex specific. ${ }^{2}$ Changes in cardiometabolic risk factors are more prevalent in women than in men, particularly before the onset of type 2 diabetes. Furthermore, visceral adipose tissue seems to be more strongly associated with cardiometabolic risk markers in women than in men. ${ }^{3}$ Moreover, genetic data corroborate the idea that visceral adiposity is a potentially independent risk factor for cardiovascular and metabolic disease in females ${ }^{4}$ emphasizing the need for a more careful analysis of this parameter.

Throughout the aging process, visceral adiposity-related comorbidities are ever more worrying. ${ }^{5}$ Anthropometric and body composition changes are common with aging, with a gradual loss of lean mass and a shift to central fat accumulation. ${ }^{6}$ This picture gets even worse when it comes to women. ${ }^{7}$ In older and obese women, visceral adiposity is strongly associated with cardiometabolic risk factors. ${ }^{8}$ For this specific population, visceral adiposity measurement can be considered a useful tool for the assessment of cardiometabolic disease risk. ${ }^{8}$ Thus, understanding the relationships between visceral adiposity, aging, and physical inactivity in women may be decisive for the design of more accurate strategies to maintain the quality of life of this population.

Visceral adiposity can be estimated by magnetic resonance imaging (MRI), by computerized tomography (CT) scan or by dual-energy X-ray absorptiometry (DXA). However, these techniques are expensive and time-consuming. In this sense, as an alternative method, the visceral adiposity index (VAI) was suggested as a marker of visceral adiposity. ${ }^{9}$ VAI is a reliable formula based on simple anthropometric data, such as body mass index (BMI) and waist circumference (WC), as well as some metabolic parameters, such as triglycerides (TG) and high-density lipoprotein (HDL). ${ }^{10}$ It is considered as a marker of adipose tissue function and distribution associated with cardiometabolic risk in the general population. ${ }^{9}$

Recent evidences showed BMI,WC, waist-to-hip ratio (WHR), waist-to-height ratio (WHtR), TG, and HDL-c ${ }^{11}$ present lower predictive parameters to quantify diabetes when compared to VAI, being an equation consisting of WC, BMI, TG/HDL-c ratio. This condition was assessed for 10 years in ATTICA Study. ${ }^{11}$ Thus, it is possible to conclude that anthropometric and biochemical variables can predict better pathological conditions related to type 2 diabetes. Therefore, given its applicability, we investigated herein possible correlations between anthropometric measurements, lipid profile, cardiorespiratory fitness, and VAI in obese older women. As a hypothesis, it is believed that VAI may be a useful instrument to verify cardiometabolic risks.

\section{METHODS}

\section{Study design and participants}

This is a cross-sectional study conducted with older women (67.1 \pm 4.9 years old) from the municipality of Maringá, State of Paraná, Brazil. Women were recruited through media releases: radio, newspaper, internet, television, and delivery folders at the Basic Health Unit (UBS), localized in University Center. All study disclosures were conducted by the University, as people participating in the study were those who lived close to the University. They were recruited for convenience. As inclusion criteria, women with the following characteristics were accepted:

- age $\geq 60$ years old;

- being overweight or obese within the cut-off ranges proposed by the Pan American Health Organization; ${ }^{12}$

- being insufficiently active, following the International Physical Activity Questionnaire (IPAQ). ${ }^{13}$

Presenting a mental or degenerative disease of the central nervous system, according to the Mini-Mental State Examination (MMSE),${ }^{14}$ was the exclusion criteria. All participants were informed about the study objectives and signed the informed consent form. All ethical and legal aspects were respected. The Research Ethics Committee approved the study with protocol n. 3.373.307/2018. Based on the responses observed in the present study, each older woman received instructions regarding her health, self-care (if possible), medical, physiotherapeutic, and nutritional referral. Also, the older women were offered community health services at the University, such as multi-professional monitoring for the treatment of obesity, composed of medical doctors, physical education professionals, physiotherapists, nutritionists, and psychologists. 


\section{Clinical evaluation}

Anamnesis was conducted to track possible pathologies, ingestion of alcoholic beverages, use of illicit drugs, cigarette consumption, continuous-use drugs, allergies, and the presence of musculoskeletal pain. Pulmonary and cardiac auscultation were verified, blood pressure was measured according to the standard established by the $7^{\text {th }}$ Brazilian Hypertension Guideline, ${ }^{15}$ and peripheral oxygen saturation $\left(\mathrm{SatO}_{2}\right)$ was consumed.

Two questionnaires were applied. One was the MMSE for cognitive performance, consisting of two parts, one covering orientation, memory, and attention, with a maximum score of 21 points. The other addressed specific skills such as naming and understanding, with a top score of 9 points, totaling a score of 30 points. ${ }^{14}$ Besides, the women completed the IPAQ short version, consisting of six open-ended questions that allowed us to verify the time spent on physical activities in days and weeks, in the most varied dimensions that included physical activities such as walking and physical exertion of moderate and vigorous-intensity. Thus, duration (minutes/day) and frequency (days/week) of physical activity were verified.

\section{Blood collection}

The collections of biochemical exams were conducted in the Clinical Analysis Laboratory of the Universidade Cesumar. All lipid profile analysis was conducted by a biomedical team blinded to other assessments. The participants were previously instructed to fast for 12 hours. Blood samples were collected by venipuncture for analysis of HDL-c, low-density lipoprotein (LDL-c), and TG. Additionally, the TG/HDL and LDL/HDL ratios were calculated. Tubes for vacuum blood collection (Vacutainer, Becton Dickinson, Plymouth, UK) were used, with clot additive gel separator. The samples were centrifuged at 3,600 rpm for 11 minutes at a controlled temperature $\left(24^{\circ} \mathrm{C}\right)$ for serum and plasma separation. For the biochemical analyses, Siemens equipment (Advia 1800 Chemistry Analyzer ${ }^{\circ}$, Siemens Healthcare Diagnostics, Illinois, United States) was used. All analyses were conducted in triplicate means by Siemens reagents (Frimley, Camberley, United Kingdom), following the fabricant's specifications.

\section{Anthropometric and body composition analysis}

Body composition analysis was performed via tetra-polar bioelectrical impedance with eight electrodes (InBody, Seoul, South Korea). The following parameters were evaluated: body weight in kg, BMI, lean mass index (LMI), fat mass index (FMI), lean mass (LM), body fat percentage, and skeletal muscle mass (SMM). Participants were instructed not to consume food and drink (solid and liquid) within 4 hours prior to the test, to urinate 30 minutes before the test, not to exercise during the last 24 hours, not to drink caffeinated beverages 12 hours before the measurement itself, and to wear light, metal-free clothing. ${ }^{16}$ Additionally, they were measured using an inextensible tape (Sanny, São Paulo, Brazil) for the WC and hip circumference (HC). The waist/hip ratio (WHR) was calculated, following the standardization proposed by Heyward. ${ }^{16}$ For anthropometric analysis, height was measured using a metal stadiometer (Sanny, São Paulo, Brazil), with a precision of $0.1 \mathrm{~cm}$. The device was fixed to the wall, and those being measured were instructed not to wear footwear, to stand with heels and knees aligned, with arms lose and positioned along the body, with palms facing the thighs, with straight legs, relaxed shoulders, and with heads in the Frankfurt plane (looking at the horizon in a straight line at eye level). ${ }^{16}$ The anthropometrical measures were conducted by a nutritional team, without access to biochemical measurements and results.

\section{Visceral adiposity index}

The VAI is a mathematical formula aiming to identify cardiometabolic risks using sex-specific equations, as well as WC in centimeters, BMI, TG, and HDL-c. Thus, the validated equation 1 for females was used, according to Amato et al.: ${ }^{17}$

$$
V A I=\frac{C C}{36,58+(1,89 \times I M C)} \times \frac{T G}{0,81} \times \frac{1,52}{H D L-c}
$$

\section{Cardiorespiratory fitness test}

The treadmill exercise test assessed the participants' functional capacity and physical performance. For the test, a heart rate monitor (Model FT1, Polar, Kempele, Finland) was worn by each participant to monitor the heart rate during exercise. It was adapted for the Bruce protocol, which is indicated for the older people, consisting of stages (with inclination and increased treadmill speed) lasting 3 minutes. In addition, 30 seconds before the end of each stage, peripheral oxygen saturation $\left(\mathrm{SpO}_{2}\right)$ was verified by a finger oximeter (G-TECHR, São Paulo, Brazil). Similarly, the women had a reading done of their rating of perceived exertion (RPE) on a scale of 6 to 20, as proposed by Borg. ${ }^{18}$ Standardization of the adapted Bruce test on the treadmill was conducted consisting of the following variations and inclinations:

- the first stage, with a speed of $2.70 \mathrm{~km} / \mathrm{h}$ without inclination; 
- the second stage, with a speed of $2.70 \mathrm{~km} / \mathrm{h}$ and $5 \%$ inclination;

- the third stage, with a speed of $2.70 \mathrm{~km} / \mathrm{h}$ and $10 \%$ inclination;

- the fourth stage, with a speed of $4 \mathrm{~km} / \mathrm{h}$ and a slope of $12 \%$;

- the fifth stage, with a speed of $5.40 \mathrm{~km} / \mathrm{h}$ and $14 \%$ inclination;

- the sixth stage, with a speed of $6.70 \mathrm{~km} / \mathrm{h}$ and a slope of $16 \%$;

- the seventh stage, with a speed of $8 \mathrm{~km} / \mathrm{h}$ and an inclination of $18 \%$;

- the eighth stage, with a speed of $8.80 \mathrm{~km} / \mathrm{h}$ and $20 \%$ slope;

- ninth stage, with a speed of $9.60 \mathrm{~km} / \mathrm{h}$ and a slope of $22 \%{ }^{19}$

\section{Direct analysis of oxygen consumption}

For direct analysis of oxygen consumption $\left(\mathrm{VO}_{2}\right)$, a metabolic gas analyzer (VO2000, Med Graphics, St. Paul, MN. USA) was used to quantify $\mathrm{VO}_{2}$ peak, with heart rate monitoring using a heart rate monitor, as well as blood pressure measurement via sphygmomanometer and standard stethoscope. Expired gases analyzed $\mathrm{VO}_{2}$ peak during the test, the duration of which was performed until voluntary exhaustion. Prior to each test, the equipment was calibrated to the manufacturer's specifications.

\section{Statistical analysis}

First, the data normality was tested using the ShapiroWilk test. After the confirmation, the data were presented in mean, standard deviation ( \pm ), and $95 \%$ confidence interval $(95 \% \mathrm{CI})$. Besides, a Pearson's correlation was applied between all variables used in the present study. All analyses were conducted by a supervisor that did not have access to any measurements performed in this study. A significance level of 5\% was adopted for all variables. We used the SPSS 22.0 (IBM, Armonk, NY, USA) to conduct the statistical analysis.

\section{RESULTS}

Table 1 presents the anthropometric measurements, body composition, lipid profile, and $\mathrm{VO}_{2}$ peak of the participants of the present study $(n=27)$.

Table 2 presents the correlations between anthropometric measurements, body composition, lipid profile, $\mathrm{VO}_{2}$ peak, and VAI of the older women participating in the present study $(\mathrm{n}=27)$.
Table 1 Anthropometric measurements, body composition, lipid profile, and $\mathrm{VO}_{2}$ peak of the older women participating in the present study $(n=27)$.

\begin{tabular}{|c|c|c|c|}
\hline Variables & Mean & SD & $95 \% \mathrm{Cl}$ \\
\hline BMI $\left(\mathrm{kg} / \mathrm{m}^{2}\right)$ & 32.80 & 6.10 & $30.70-35.00$ \\
\hline LMI $\left(\mathrm{kg} / \mathrm{m}^{2}\right)$ & 17.90 & 2.00 & $17.20-18.60$ \\
\hline FMI $\left(\mathrm{kg} / \mathrm{m}^{2}\right)$ & 14.90 & 4.70 & $13.30-16.50$ \\
\hline WC (cm) & 103.80 & 13.40 & $99.00-108.80$ \\
\hline $\mathrm{HC}(\mathrm{cm})$ & 115.60 & 11.70 & $111.50-120.70$ \\
\hline WHR $(\mathrm{cm} / \mathrm{cm})$ & 0.90 & 0.10 & $0.87-0.93$ \\
\hline LM (kg) & 45.50 & 7.20 & $43.00-48.30$ \\
\hline FM (kg) & 37.50 & 11.20 & $33.50-41.80$ \\
\hline SMM (kg) & 24.80 & 4.20 & $23.30-26.50$ \\
\hline $\mathrm{HDL}(\mathrm{mg} / \mathrm{dL})$ & 49.60 & 10.40 & $45.40-53.30$ \\
\hline LDL (mg/dL) & 97.30 & 37.70 & $84.20-112.10$ \\
\hline $\mathrm{TG}(\mathrm{mg} / \mathrm{dL})$ & 139.00 & 90.30 & $109.20-178.40$ \\
\hline $\mathrm{TG} / \mathrm{HDL}$ (mg/dL) & 3.10 & 2.70 & $2.30-4.30$ \\
\hline LDL/HDL (mg/dL) & 2.00 & 0.80 & $1.70-2.30$ \\
\hline $\begin{array}{l}\mathrm{VO}_{2} \text { peak } \\
\left(\mathrm{mL} \cdot \mathrm{kg}^{-1} \cdot \mathrm{min}^{-1}\right)\end{array}$ & 19.00 & 5.10 & $17.00-20.80$ \\
\hline VAl & 6.00 & 4.80 & $4.40-8.30$ \\
\hline
\end{tabular}

SD: standard deviation; 95\%Cl: 95\% confidence interval; BMl: body mass index; LMI: lean mass index; FMI: fat mass index; WC: waist circumference; HC: hip circumference; WHR: waist-hip ratio; LM: lean mass; FM: fat mass; SMM: skeletal muscle mass; HDL: high density lipoproteins; LDL: low density lipoproteins; TG: triglycerides; $\mathrm{VO}_{2}$ peak: peak oxygen consumption; VAl: visceral adiposity index.

\section{DISCUSSION}

Considering the main objective of the present study was to evaluate possible correlations between anthropometric measurements, lipid profile, cardiorespiratory fitness and VAI in obese older women, the main results observed were:

- VAI and HDL-c $(r=-0.53)$;

- VAI and LDL-c $(\mathrm{r}=-0.35)$;

- VAI and TG $(\mathrm{r}=0.86)$;

- (d) VAI and TG/HDL ( $r=0.99)$;

- VAI and $\mathrm{VO}_{2}$ peak $(\mathrm{r}=-0.55)$.

Secondarily, the following correlations were observed:

- $\mathrm{VO}_{2}$ peak and LDL/HDL $(\mathrm{r}=-0.58)$;

- $\mathrm{VO}_{2}$ peak and LDL-c $(\mathrm{r}=-0.39)$;

- $\mathrm{VO}_{2}$ peak and $\mathrm{FM}(\mathrm{r}=-0.46)$;

- $\mathrm{VO}_{2}$ peak and $\mathrm{HC}(\mathrm{r}=-0.43)$; 
Table 2 Correlations between anthropometric measurements, body composition, lipid profile, $\mathrm{VO}_{2}$ peak, and VAI of the older women participating in the present study $(n=27)$.

\begin{tabular}{|c|c|c|c|c|c|c|c|c|c|c|c|c|c|c|c|c|}
\hline & BMI & LMI & FMI & WC & $\mathrm{HC}$ & WHR & LM & FM & SMM & HDL & LDL & TG & TG/HDL & $\begin{array}{l}\text { LDL/ } \\
\text { HDL }\end{array}$ & $\begin{array}{l}\mathrm{VO}_{2} \\
\text { peak }\end{array}$ & VAI \\
\hline BMI & 1.00 & $0.82^{* *}$ & $0.97^{* *}$ & $0.75^{* *}$ & $0.94^{* *}$ & -0.03 & $.50^{* *}$ & $0.96^{* *}$ & $0.52^{* *}$ & $-0.39^{*}$ & -0.12 & 0.13 & 0.25 & 0.07 & $-0.39^{*}$ & 0.24 \\
\hline LMI & $0.82^{* *}$ & 1.00 & $0.82^{* *}$ & $0.64^{* *}$ & $0.71^{* *}$ & 0.10 & $0.82^{* *}$ & $0.70^{* *}$ & $0.83^{* *}$ & -0.27 & -0.28 & 0.14 & -0.18 & -0.15 & -0.08 & 0.14 \\
\hline FMI & $0.97^{* *}$ & $0.64^{* *}$ & 1.00 & $0.71^{* *}$ & $0.93^{* *}$ & -0.08 & 0.30 & $0.96^{* *}$ & 0.32 & $-0.39^{*}$ & -0.03 & 0.10 & 0.24 & 0.16 & $-0.47^{* *}$ & 0.17 \\
\hline WC & $0.75^{* *}$ & $0.64^{* *}$ & $0.71^{* *}$ & 1.00 & $0.74^{* *}$ & $0.55^{* *}$ & $0.61^{* *}$ & $0.71^{* *}$ & $0.61^{* *}$ & -0.36 & -0.29 & -0.07 & 0.06 & -0.15 & -0.34 & 0.07 \\
\hline $\mathrm{HC}$ & $0.94^{* *}$ & $0.71^{* *}$ & $0.93^{* *}$ & $0.74^{* *}$ & 1.00 & -0.11 & $0.48^{* *}$ & $0.94^{* *}$ & $0.49^{* *}$ & $-0.34^{*}$ & -0.02 & -0.04 & 0.11 & 0.12 & $-0.43^{*}$ & 0.04 \\
\hline WHR & -0.02 & 0.10 & -0.08 & $0.54^{* *}$ & -0.11 & 1.00 & $0.33^{*}$ & 0.03 & $0.33^{*}$ & -0.09 & $-0.54^{* *}$ & -0.03 & -0.06 & $-0.53^{* *}$ & 0.18 & 0.03 \\
\hline LM & $.50^{* *}$ & $0.82^{* *}$ & 0.30 & $0.61^{* *}$ & $0.48^{* *}$ & $0.33^{*}$ & 1.00 & $0.51^{* *}$ & $0.99 * *$ & -0.23 & $-0.37^{*}$ & 0.02 & 0.14 & -0.27 & 0.01 & 0.14 \\
\hline FM & $0.96^{* *}$ & $0.70^{* *}$ & $0.96^{* *}$ & $0.80^{* *}$ & $0.94^{* *}$ & 0.03 & $0.51^{* *}$ & 1.00 & $0.52^{* *}$ & $-0.41^{*}$ & -0.09 & 0.09 & 0.27 & 0.09 & $-0.46^{* *}$ & 0.21 \\
\hline SMM & $0.52^{* *}$ & $0.83^{* *}$ & 0.32 & $0.61^{* *}$ & $0.49^{* *}$ & $0.33^{*}$ & $0.99^{* *}$ & $0.52^{* *}$ & 1.00 & -0.24 & $-0.38^{*}$ & 0.04 & 0.15 & -0.28 & 0.00 & 0.16 \\
\hline HDL & $-0.38^{*}$ & -0.27 & $-0.39^{*}$ & $-0.36^{*}$ & -0.34 & -0.09 & -0.23 & $-0.41^{*}$ & -0.24 & 1.00 & 0.25 & -0.12 & $-0.51^{* *}$ & -0.25 & 0.31 & $-0.53^{* *}$ \\
\hline LDL & -0.11 & -0.28 & -0.03 & -0.29 & -0.02 & $-0.54^{* *}$ & $-0.37^{*}$ & -0.09 & $-0.38^{*}$ & 0.25 & 1.00 & -0.31 & -0.29 & $0.85^{* *}$ & $-0.39^{*}$ & $0.35^{*}$ \\
\hline TG & 0.12 & 0.14 & 0.10 & -0.07 & -0.04 & -0.03 & 0.02 & 0.09 & 0.04 & -012 & -0.31 & 1.00 & $0.87^{* *}$ & -0.11 & -0.04 & $0.86^{* *}$ \\
\hline TG/HDL & 0.24 & 0.18 & 0.24 & 0.06 & 0.15 & -0.06 & 0.14 & 0.27 & 0.15 & $-0.51^{* *}$ & -0.29 & $0.87^{* *}$ & 1.00 & 0.08 & -0.29 & $0.99^{* *}$ \\
\hline LDL/HDL & 0.07 & -0.14 & 0.15 & -0.15 & 0.12 & $-0.53^{* *}$ & -0.27 & 0.09 & -0.28 & -0.25 & $0.85^{* *}$ & -0.11 & 0.08 & 1.00 & $-0.58^{* *}$ & 0.02 \\
\hline $\mathrm{VO}_{2}$ peak & $-0.39^{*}$ & -0.08 & $-0.47^{* *}$ & $-0.34^{*}$ & $-0.43^{*}$ & 0.18 & 0.01 & $-0.46^{* *}$ & 0.00 & 0.31 & $-0.39^{*}$ & -0.04 & -0.29 & $-0.58^{* *}$ & 1.00 & $-0.55^{* *}$ \\
\hline VAI & 0.17 & 0.13 & 0.16 & 0.07 & 0.04 & 0.03 & 0.14 & 0.21 & 0.13 & $-0.53^{* *}$ & $0.35^{*}$ & $0.86^{* *}$ & $0.99 * *$ & 0.02 & $-0.55^{* *}$ & 1.00 \\
\hline
\end{tabular}

BMI: body mass index; LMI: lean mass index; FMI: fat mass index; WC: waist circumference; HC: hip circumference; WHR: waist-hip ratio; LM: lean mass; FM: fat mass; SMM: skeletal muscle mass; HDL: high density lipoproteins; LDL: low density lipoproteins; TG: triglycerides; $\mathrm{VO}_{2}$ peak: peak oxygen consumption; VAl: visceral adiposity index; ${ }^{*}=<0,05 ;{ }^{* *}=<0,01$.

- $\mathrm{VO}_{2}$ peak and $\mathrm{WC}(\mathrm{r}=-0.34)$;

- $\mathrm{VO}_{2}$ peak and BMI $(\mathrm{r}=-0.47)$;

- $\mathrm{VO}_{2}$ peak and BMI $(\mathrm{r}=-0.39)$.

The negative correlation detected between VAI and HDL-c may be associated with increased cardiometabolic risk, increased adipose tissue, and reduced sensitivity to insulin action, as demonstrated previously by other study. ${ }^{20}$ In this case, the higher the VAI, it is suggested, the lower the HDL-c. ${ }^{21}$ These also suggest that the elevation of LDL-c and serum TG increase the cardiometabolic risk in sedentary people. The literature points to biomarkers of inflammation that show anthropometric parameters in the obese older people, in addition to vascular damage, resistance to insulin action, and atherosclerosis. ${ }^{22}$ The higher the VAI, the higher the TG/LDL and LDL/HDL ratios, as visceral risk factors. ${ }^{9}$

Thus, the TG/LDL and LDL/HDL ratios can be incorporated as a cardiometabolic risk assessment instrument in blood tests, since preventive measures and treatment can be performed to improve the quality of life of people. Another point that can be emphasized is the incorporation of the calculation of VAI in biochemical exams at the time the evaluated patients have their body weight and height measured. Thus, considering that VAI has cut-off points that indicate risks associated with visceral adiposity, ${ }^{17}$ health professionals will note possible risks related to visceral adiposity in a less expensive way, as VAI and imaging exams are interconnected as to the risks of visceral adiposity. ${ }^{12}$ Postmenopausal women with high TG/ HDL ratio are also associated with a higher likelihood of carotid plaque deposition. ${ }^{23}$ However, it should be highlighted that image diagnostics such as MRI, CT, and DXA are, in fact, the gold standard measurements. Although there are limitations regarding the use of anthropometry to estimate health risks, the use of the lipid profile and VAI together can be interesting strategies (considering their respective limitations) in the first levels of primary health care. 
Therefore, another point that can be considered is the elaboration of cut-off ranges based on the TG/HDL ratio, intending to provide risk indicators, so that the health professional promotes more assertive behaviors to the evaluated public. Within the context of health promotion, especially in senescence, the limitation of gait speed is related to the reduction of activities of daily living and, consequently, favors functional disability and increased fat mass, which is closely associated to the low energy expenditure added to the high caloric consumption. ${ }^{24}$ Preventive and therapeutic measures are recommended to promote health in the older people, such as the encouragement of physical exercise, including resistance and aerobic exercises..$^{25}$

The incorporation of regular aerobic exercise is fundamental in this age range because the results of the present study have suggested that the $\mathrm{VO}_{2}$ peak is inversely correlated with VAI. In this sense, low values of $\mathrm{VO}_{2}$ peak are related to lower life expectancy. Besides that, the increase in $\mathrm{BMI}$ is negatively correlated with $\mathrm{VO}_{2}$ peak, and low aerobic fitness is related to shorter life expectancy. ${ }^{26}$ Thus, the incorporation of aerobic exercises in a physical activity program for older adults is indispensable for the maintenance of cardiovascular health. Also, fat mass, BMI, and high BMI are correlated with reduced aerobic fitness. The decrease in $\mathrm{VO}_{2}$ peak in women with senescence is greater than in men and is related to cardiorespiratory disease in aging. ${ }^{27}$ Weight reduction associated with physical activity represents a decrease in myocardial damage, such as heart failure in the obese. ${ }^{28}$

Another point that cannot be overlooked to improve the older people quality of life and consequent healthy aging is a substantial awareness and stimulus for physical activity, especially resistance exercises, to maintain and even increase muscle mass in order to improve functional capacity and reduce physical inactivity and risks associated with falls. ${ }^{29}$ In overweight individuals, waist circumference does not differ from the visceral adipose tissue from the cutaneous adipose tissue. ${ }^{30}$ In this context, the present study indicated negative correlations between $\mathrm{VO}_{2}$ peak and $\mathrm{WC}$ and $\mathrm{HC}$, suggesting that circumferences may negatively impact aerobic fitness. It is further emphasized that being overweight and being obese are risk factors among older adults for the acquisition of mild cognitive impairment. ${ }^{31}$

Finally, it is relevant to emphasize that, in general, obesity and sedentary lifestyle in the older women population are related to cardiovascular risk. Given this, the incorporation of preventive strategies to increase physical activity, healthy food consumption, and HDL-c, reducing sedentary time, as well as decreasing obesity, insulin resistance, LDL-C, very-low-density lipoprotein (VLDL-c), and TG, can improve vascular aging. ${ }^{32}$ Despite the essential data presented, this study has some limitations. First, the cross-sectional design, which prevents inferring causality. Second, the non-probabilistic and small sample, which prevents the generalization of the results.

\section{CONCLUSION}

VAI is associated with lipid profile and cardiorespiratory fitness in older women, with negative correlations between $\mathrm{HDL}-\mathrm{c}$ and $\mathrm{VO}_{2}$ peak, suggesting these variables are negatively influenced by visceral adiposity. Besides, TG, LDL-c, and TG/HDL showed positive correlations with VAI. These responses recommend other analyses in order to confirm possible risks for health. In addition, the responses of the present study advocate that VAI may be used as a cardiometabolic risk marker, especially among obese older women. It is suggested that further studies may be conducted combining VAI, diet, and socioeconomic conditions to identify the presence of these changes. Given the aspects explored in this study, it is evident that obesity is a worrying factor in aging, and its risks can be easily detected by professionals in various health areas in their clinical practice. More studies are needed to better understand the applicability of VAI as a cardiometabolic risk factor indicator in older adults.

\section{CONFLICT OF INTERESTS}

The authors declare no conflict of interests.

\section{FUNDING}

None.

\section{AUTHORS' CONTRIBUTION}

ARC: conceptualization, data curation, writing - original draft. DVO: writing - original draft. PVB: writing - original draft, formal analysis. MPB: formal analysis. SMMGB: writing - original draft. BHMB: conceptualization, data curation, writing - original draft. 


\section{REFERENCES}

1. Wolever RQ, Simmons LA, Sforzo GA, Dill D, Kaye M, Bechard EM, et al. A Systematic Review of the Literature on Health and Wellness Coaching: Defining a Key Behavioral Intervention in Healthcare. Glob Adv Heal Med. 2013;2(4):38-57. https://dx.doi. org/10.7453\%2Fgahmj.2013.042

2. Gerdts E, Regitz-Zagrosek V. Sex differences in cardiometabolic disorders. Nat Med. 2019;25(11):1657-66. https://doi.org/10.1038/ s41591-019-0643-8

3. Schorr M, Dichtel LE, Gerweck AV, Valera RD, Torriani M, Miller KK, et al. Sex differences in body composition and association with cardiometabolic risk. Biol Sex Differ. 2018;9(1):28. https://doi.org/10.1186/s13293-018-0189-3

4. Karlsson T, Rask-Andersen M, Pan G, Höglund J, Wadelius C, Ek WE, et al. Contribution of genetics to visceral adiposity and its relation to cardiovascular and metabolic disease. Nat Med. 2019;25(9):1390-5. https://doi.org/10.1038/s41591-019-0563-7

5. Santanasto AJ, Goodpaster BH, Kritchevsky SB, Miljkovic I, Satterfield S, Schwartz AV, et al. Body Composition Remodeling and Mortality: The Health Aging and Body Composition Study. J Gerontol A Biol Sci Med Sci. 2017;72(4):513-9. https://dx.doi.org/10.1093\%2Fgerona\%2Fglw163

6. Vlassopoulos A, Combet E, Lean MEJ. Changing distributions of body size and adiposity with age. Int J Obes. 2014;38(6):857-64. https:// doi.org/10.1038/ijo.2013.216

7. Ambikairajah A, Walsh E, Tabatabaei-Jafari H, Cherbuin N. Fat mass changes during menopause: a metaanalysis. Am J Obstet Gynecol. 2019;221(5):393-409.e50. https://doi.org/10.1016/j.ajog.2019.04.023

8. Elffers TW, Mutsert R, Lamb HJ, Roos A, Willems van Dijk K, Rosendaal $\mathrm{FR}$, et al. Body fat distribution, in particular visceral fat, is associated with cardiometabolic risk factors in obese women. He M, editor. PLoS One. 2017;12(9):e0185403. https://dx.doi.org/10.1371\%2Fjournal. pone.0185403

9. Amato MC, Pizzolanti G, Torregrossa V, Misiano G, Milano S, Giordano C. Visceral Adiposity Index (VAI) Is Predictive of an Altered Adipokine Profile in Patients with Type 2 Diabetes. Chowen JA, editor. PLoS One. 2014;9(3):e91969. https://doi.org/10.1371/journal.pone.0091969

10. Kang YM, Jung CH, Cho YK, Jang JE, Hwang JY, Kim EH, et al. Visceral adiposity index predicts the conversion of metabolically healthy obesity to an unhealthy phenotype. PLoS One. 2017;12(6):e0179635. https:// doi.org/10.1371/journal.pone.0179635

11. Koloverou E, Panagiotakos DB, Kyrou I, Stefanadis C, Chrysohoou C, Georgousopoulou EN, et al. Visceral adiposity index outperforms common anthropometric indices in predicting 10-year diabetes risk: Results from the ATTICA study. Diabet Metab Rev. 2019;35(6):e3161. https://doi.org/10.1002/dmrr.3161

12. Pan American Health Organization. Strategy for the Prevention and Control of Noncommunicable Diseases. 28th PAN Am Sanit Conf 64th Sess Reg Comm. Pan American Health Organization; 2012.

13. Matsudo S, Araújo T, Matsudo V, Andrade D, Andrade E, Oliveira LCGB, et al. Questionário internacional de atividade física (IPAQ): estudo de validade e reprodutibilidade no Brasil. Rev Bras Atividade Física Saúde. 2001;6(2):5-18. https://doi.org/10.12820/rbafs.v.6n2p5-18

14. Folstein MF, Folstein SE, McHugh PR. "Mini-mental state”. A practical method for grading the cognitive state of patients for the clinician. J Psychiatr Res. 1975;12(3):189-98. https://doi.org/10.1016/00223956(75)90026-6

15. Malachias MVB, Souza WKSB, Plavnik FL, Rodrigues CIS, Brandão AA, Neves MFT, et al. 7a Diretriz Brasileira de Hipertensão Arterial. Arq Bras Cardiol. 2016;107(3 Suppl. 3).

16. Heyward V. ASEP Methods recommendation: body composition assessment. J Exerc Physiol. 2001;4(4):1-12.

17. Amato MC, Giordano C, Galia M, Criscimanna A, Vitabile S, Midiri $\mathrm{M}$, et al. Visceral Adiposity Index: A reliable indicator of visceral fat function associated with cardiometabolic risk. Diabetes Care. 2010;33(4):920-2. https://doi.org/10.2337/dc09-1825

18. Borg GAV. Psychophysical bases of perceived exertion. Med Sci Sports Exerc. 1982;14(5):377-81.

19. Bruce RA, Blackmon JR, Jones JW, Strait G. Exercising testing in adult normal subjects and cardiac patients. Ann Noninvasive Electrocardiol. 2004;9(3):291-303. https://dx.doi.org/10.1111\%2Fj.1542474X.2004.93003.X

20. Vogel P, Stein A, Marcadenti A. Visceral adiposity index and prognosis among patients with ischemic heart failure. Sao Paulo Med J. 2016;134(3):211-8. http://dx.doi.org/10.1590/15163180.2015.01452111

21. Paula HAA, Ribeiro RCL, Rosado LEFPL, Pereira RSF, Franceschini S do CC. Comparação de diferentes critérios de definição para diagnóstico de síndrome metabólica em idosas. Arq Bras Cardiol. 2010;95(3):34653. http://dx.doi.org/10.1590/50066-782X2010005000100

22. Milagres LC, Martinho KO, Milagres DC, Franco FS, Ribeiro AQ, Novaes JF de. Relação cintura/estatura e índice de conicidade estão associados a fatores de risco cardiometabólico em idosos. Ciên Saúde Colet. 2019;24(4):1451-61. http://dx.doi.org/10.1590/141381232018244.12632017

23. Masson W, Lobo M, Molinero G, Siniawski D. Discordant Lipid Pattern and Carotid Atherosclerotic Plaque. Importance of Remnant Cholesterol. Arq Bras Cardiol. 2017;108(6):526-32. http://dx.doi.org/10.5935/ abc.20170069.

24. Heiland EG, Welmer A-K, Wang R, Santoni G, Fratiglioni L, Qiu C. Cardiovascular Risk Factors and the Risk of Disability in Older Adults: Variation by Age and Functional Status. J Am Med Dir Assoc. 2019;20(2):208-212.e3. https://doi.org/10.1016/j.jamda.2018.05.013

25. Nelson ME, Rejeski WJ, Blair SN, Duncan PW, Judge JO, King AC, et al. Physical activity and public health in older adults: Recommendation from the American College of Sports Medicine and the American Heart Association. Med Sci Sports Exerc. 2007;39(8):1435-45. https://doi. org/10.1249/mss.0b013e3180616aa2

26. Cancino-López J, Olivares-Gálvez M, Maiz-Hohlberg C, Soto-Sánchez J, Palacio-Agüero A, Pino-Zúñiga J. Potencia aeróbica máxima en el obeso: Valores de referencia. Rev Med Chil. 2019;147(3):289-95. http://dx.doi.org/10.4067/S0034-98872019000300289

27. Ekblom-Bak E, Ekblom B, Söderling J, Börjesson M, Blom V, Kallings LV et al. Sex- and age-specific associations between cardiorespiratory fitness, CVD morbidity and all-cause mortality in in 266.109 adults. Prev Med. 2019;127:105799. https://doi.org/10.1016/j.ypmed.2019.105799

28. Florido R, Ndumele CE, Kwak L, Pang Y, Matsushita K, Schrack JA, et al Physical Activity, Obesity, and Subclinical Myocardial Damage. JACC Hear Fail. 2017;5(5):377-84. https://doi.org/10.1016/j.jchf.2017.02.002

29. Janini JP, Bessler $D$, Vargas $A B$. Educação em saúde e promoção da saúde: impacto na qualidade de vida do idoso. Saúde Debate. 2015;39(105):480-90. https://doi.org/10.1590/0103110420151050002015

30. Bosy-Westphal A, Booke C-A, Blöcker T, Kossel E, Goele K, Later W, et al. Measurement Site for Waist Circumference Affects Its Accuracy As an Index of Visceral and Abdominal Subcutaneous Fat in a Caucasian Population. J Nutr. 2010;140(5):954-61. https://doi.org/10.3945/ jn.109.118737

31. Wang F, Zhao M, Han Z, Li D, Zhang S, Zhang Y, et al. Association of body mass index with amnestic and non-amnestic mild cognitive impairment risk in elderly. BMC Psychiatry. 2017;17(1):334. https:// doi.org/10.1186/s12888-017-1493-x

32. Gomez-Sanchez M, Gomez-Sanchez L, Patino-Alonso MC, Cunha PG, Recio-Rodriguez JI, Alonso-Dominguez R, et al. Vascular aging and its relationship with lifestyles and other risk factors in the general Spanish population: Early Vascular Ageing Study. J Hypertens. 2020;38(6):111022. https://doi.org/10.1097/hjh.0000000000002373 